\title{
LTX-315 - a promising novel antitumor peptide and immunotherapeutic agent
}

\author{
Dagmar Zweytick ${ }^{1,2, *}$ \\ ${ }^{1}$ Institute of Molecular Biosciences, Biophysics Division, University of Graz, Graz, Austria. \\ 2 BioTechMed-Graz, Graz, Austria. \\ * Corresponding Author: \\ Dagmar Zweytick, Phone: +43 316 4988; E-mail: dagmar.zweytick@uni-graz.at
}

Host defense in mammals, as provided by the innate immune system, comprises proteins such as lactoferrin (LF), a multifunctional iron-binding glycoprotein originally discovered in bovine milk. LF is further pepsin-cleaved to a cationic amphipathic peptide, lactoferricin (LFcin; amino acid 1-45 of LF), which is known for its antimicrobial, antiseptic, antiviral, antitumor and immunomodulatory activities [13]. Bovine LFcin has been shown to inhibit liver and lung metastasis of both murine melanomas and lymphomas [4] and to induce apoptosis in human leukemic and carcinoma cell lines [5, 6]. LTX-315 [7] and LTX-302 [8], which derived of bovine LFcin by structural optimization, contain amongst others - the non-coded residue $\beta$-diphenylalanine and show increased activity in vivo by peptide induced tumor regression and infiltration of the tumor by immune cells. LTX-315 is effective against multiple tumor types, and is therefore studied as novel immunotherapeutic agent in phase $\mathrm{I} / \mathrm{II}$ clinical trials in combination with checkpoint inhibitors for treatment of advanced solid tumors, using the ability to reduce tumor growth and to induce de novo T-cell responses [9].

In the current issue of Cell Stress, Pittet and colleagues evaluated LTX-315 in conditional genetic mouse models of melanoma and sarcoma that are so far mainly resistant to standard treatment. Therefore, syngeneic grafts of murine melanoma B16F10, Braf- and Pten-driven melanoma as well as Kras- and P53-driven soft tissue sarcoma were studied in mice regarding their sensitivity towards LTX-315. These mutations are an ideal model, since they are often found in human patients suffering of these cancer types, as well are these tumor models, as also murine melanoma B16F10, poorly infiltrated by $T$ cells and resistant to immune checkpoint therapy. The authors show a two-phase response in the tumor models triggered by the intratumor- al injection with the peptide. The first phase of response is a rapid (within minutes) disruption of tumor vasculature and decrease of tumor burden. This direct antitumor effect seems to occur by induced cell lysis blocking the oxygen and nutrients supply by the tumor vasculature without the help of antitumor lymphocytes. The second phase of response is however as important for the antitumor (longterm) effect of the peptide. It endures over several weeks and is characterized by a tumor infiltration with CD8+ $T$ cells that is normally very poor in the described tumor models and can display antitumor functions. Further, immune cells such as CD4+ T cells and natural killer (NK) cells were shown to migrate into the tumor environment upon treatment with LTX-315. This effect of triggering an antitumor immune response was more pronounced in the melanoma than in the sarcoma models, which might be due to the lower mutational load of the latter. However, this long-term conversion of a poorly to a highly immunogenic tumor promises a long-term antitumor immunity by prevention of tumor regrowth after treatment.

Malignant melanoma and fibrosarcoma both exhibit poor treatability and prognosis and therefore demand for new therapy, such as LTX-315 studied within the current issue by Pittet and colleagues. Depending on the progression, surgery, classical radio- and chemotherapy are applied for the treatment of malignant melanoma, though therapeutic options are limited due to metastasis and chemo-resistance [10]. In the last years, targeted- and immunotherapies (e.g. CTLA4-, PDL1/2- and BRAF inhibitors) have been developed and are promising to be more specific and exhibit less side effects [11]. However, these therapies also only yield limited improvement of survival and even here resistances are observed towards MAPK inhibitors (BRAF and MEK inhibitors) and immunotherapeutic

Comment on this issue's Hsin-Wei Liao, Christopher Garris, Christina Pfirschke, Steffen Rickelt, Sean Arlauckas, Marie Siwicki, Rainer H. Kohler, Ralph Weissleder, Vibeke Sundvold-Gjerstad, Baldur Sveinbjørnsson, Øystein Rekdal and Mikael J. Pittet (2019). LTX-315 sequentially promotes lymphocyte-independent and lymphocyte-dependent antitumor effects. Cell Stress 3(11): 348-360. doi: 10.15698/cst2019.11.204

\author{
doi: $10.15698 /$ cst2019.11.202 \\ Received originally: 29.10.2019, Accepted 30.10.219, Published 03.11.2019. \\ Keywords: antitumor peptide, immunotherapeutic agent, melanoma, sarcoma.
}


drugs like CTLA4 inhibitors [12]. Fibrosarcoma is a rare but highly malignant soft tissue tumor with a low sensitivity towards radio- and chemotherapy, as well as a high rate of reoccurrence and therefore poor prognosis [13].

Thus, in urgent need of new antitumor therapies and based on the results that LTX-315 triggers CD8+ $T$ cell accumulation in the mouse models, two melanoma and two sarcoma patients were treated with LTX-315 intratumorally. Biopsy evaluation by histology revealed peptide treatment induced CD3+ and CD8+ infiltration of both tumor types in all four patients, providing evidence for a promising use in clinical therapy against these cancer types. The ability of the peptide to convert a "cold" into a "hot" (immunogenic) tumor further encourages a combinational therapy of LTX-315 with checkpoint inhibitors. A triple effect could be provoked by (i) direct disruption of the tumor by LTX-315, (ii) attack by immune cells induced by check-

\section{REFERENCES}

1. Bellamy W, Takase M, Wakabayashi H, Kawase K, Tomita M (1992). Antibacterial spectrum of lactofericin $B$, a potent bactericidal peptide derived from the $\mathrm{N}$-terminal region of bovine lactoferrin. J Appl Bacteriol 73 (6):472-479. doi: 10.1111/j.1365-2672.1992.tb05007.x

2. Gifford JL, Hunter HN, Vogel HJ (2005). Lactoferricin: a lactoferrinderived peptide with antimicrobial, antiviral, antitumor and immunological properties. Cell Mol.Life Sci 62(22):2588-2598. doi: 10.1007/s00018-005-5373-z

3. Sorenson M, Sorenson MPL (1939). The proteins in whey. CR Trav Lab Carlsberg 23:55-59.

4. Yoo YC, Watanabe S, Watanabe R, Hata K, Shimazaki K, Azuma I (1997). Bovine lactoferrin and lactoferricin, a peptide derived from bovine lactoferrin, inhibit tumor metastasis in mice. Jpn J Cancer Res 88:184-190. doi: 10.1111/j.1349-7006.1997.tb00364.x

5. Eike L-M, Yang N, Rekdal $\varnothing$, Sveinbjørnsson B (2015). The oncolytic peptide LTX-315 induces cell death and DAMP release by mitochondria distortion in human melanoma cells. Oncotarget 6:34910-34923. doi: 10.18632/oncotarget.5308

6. Mader JS, Salsman J, Conrad DM, Hoskin DW (2005). Bovine lactoferricin selectively induces apoptosis in human leukemia and carcinoma cell lines. Mol Cancer Ther 4 (4):612-624. doi: 10.1158/15357163.mct-04-0077

7. Camilio KA, Berge G, Ravuri CS, Rekdal O, Sveinbjornsson B (2014). Complete regression and systemic protective immune responses obtained in B16 melanomas after treatment with LTX-315. Cancer Immunol Immunother 63(6):601-613. doi: 10.1007/s00262-014-1540-0 point inhibitors such as anti-CTLA4 and finally (iii) a stop of regrowth by peptide induced antitumor immunity.

\section{CONFLICT OF INTEREST \\ No conflict of interest.}

\section{COPYRIGHT}

(C) 2019 Zweytick. This is an open-access article released under the terms of the Creative Commons Attribution (CC BY) license, which allows the unrestricted use, distribution, and reproduction in any medium, provided the original author and source are acknowledged.

Please cite this article as: Dagmar Zweytick (2019). LTX-315 - a promising novel antitumor peptide and immunotherapeutic agent Cell Stress 3(11): 328-329. doi: 10.15698/cst2019.11.202

8. Berge G, Eliassen LT, Camilio KA, Bartnes K, Sveinbjornsson B, Rekdal O (2010). Therapeutic vaccination against a murine lymphoma by intratumoral injection of a cationic anticancer peptide. Cancer Immunol Immunother 59:1285-1294. doi: 10.1007/s00262-010-08576

9. Camilio KA, Rekdal O, Sveinbjornsson B (2014). LTX-315 (Oncopore): A short synthetic anticancer peptide and novel immunotherapeutic agent. Oncoimmunology 3(6): e29181. doi: 10.4161/onci.29181

10. Kalal BS, Upadhya D, Pai VR (2017). Chemotherapy Resistance Mechanisms in Advanced Skin Cancer. Oncol Rev 11:326. doi: 10.4081/oncol.2017.326

11. Maverakis E, Cornelius LA, Bowen GM, Phan T, Patel FB, Fitzmaurice $S$, He $Y$, Burrall B, Duong C, Kloxin AM, Sultani H, Wilken R, Martinez SR, Patel $F$ (2015). Metastatic melanoma - a review of current and future treatment options. Acta Derm Venereol 95:516-524. doi: 10.2340/00015555-2035

12. Winder M, Virós A (2018). Mechanisms of Drug Resistance in Melanoma. Handb Exp Pharmacol 249:91-108. doi: 10.1007/164_2017_17

13. Augsburger D, Nelson PJ, Kalinski T, Udelnow A, Knösel T, Hofstetter M, Qin JW, Wang Y, Gupta AS, Bonifatius S, Li M, Bruns CJ, Zhao Y (2017). Current diagnostics and treatment of fibrosarcoma perspectives for future therapeutic targets and strategies. Oncotarget 8:104638-104653. doi: 10.18632/oncotarget.20136 